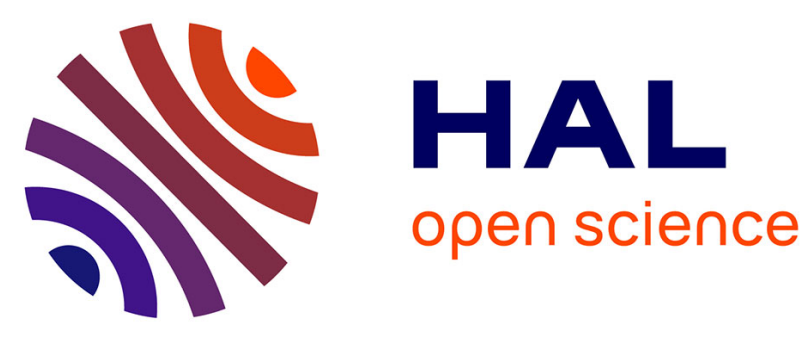

\title{
Fiber evanescent wave spectroscopy based on IR fluorescent chalcogenide fibers
}

Radwan Chahal, Florent Starecki, Catherine Boussard-Plédel, Jean-Louis

Doualan, Karine Michel, Laurent Brilland, Alain Braud, Patrice Camy, Bruno

Bureau, Virginie Nazabal

\section{To cite this version:}

Radwan Chahal, Florent Starecki, Catherine Boussard-Plédel, Jean-Louis Doualan, Karine Michel, et al.. Fiber evanescent wave spectroscopy based on IR fluorescent chalcogenide fibers. Sensors and Actuators B: Chemical, 2016, 229, pp.209-216. 10.1016/j.snb.2016.01.091 . hal-01269748

HAL Id: hal-01269748

https://hal-univ-rennes1.archives-ouvertes.fr/hal-01269748

Submitted on 22 Apr 2016

HAL is a multi-disciplinary open access archive for the deposit and dissemination of scientific research documents, whether they are published or not. The documents may come from teaching and research institutions in France or abroad, or from public or private research centers.
L'archive ouverte pluridisciplinaire HAL, est destinée au dépôt et à la diffusion de documents scientifiques de niveau recherche, publiés ou non, émanant des établissements d'enseignement et de recherche français ou étrangers, des laboratoires publics ou privés. 


\section{Fiber Evanescent Wave Spectroscopy based on IR fluorescent chalcogenide}

\section{fibers}

Radwan CHAHAL ${ }^{1}$, Florent STARECKI ${ }^{1}$, Catherine BOUSSARD-PLÉDEL ${ }^{1}$, Jean-Louis DOUALAN ${ }^{2}$, Karine MICHEL $^{3}$, Laurent BRILLAND ${ }^{4}$, Alain BRAUD ${ }^{2}$, Patrice CAMY ${ }^{2}$, Bruno BUREAU $^{1}$, Virginie NAZABAL ${ }^{1 *}$

${ }^{1}$ Equipe Verres et Céramiques - Institut des Sciences Chimiques de Rennes (ISCR), UMR 6226

Université de Rennes 1-CNRS, Campus de Beaulieu, 35042 Rennes Cedex, France

${ }^{2}$ Centre de recherche sur les Ions, les Matériaux et la Photonique (CIMAP), UMR 6252 CEA-CNRS-

ENSI Caen, Université de Caen, 14050 Caen, France

${ }^{3}$ Bureau de Recherches Géologiques \& Minières, F-45060 Orléans, France

${ }^{4}$ PERFOS, R\&D Platform from Photonics Bretagne, 11 rue Louis de Broglie, 22300 Lannion, France

Corresponding-Author: Dr. V. Nazabal (E-mail : virginie.nazabal@univ-rennes1.fr, Institut Sciences Chimiques de Rennes, Equipe Verres \& Céramiques - UMR-CNRS 6226 Université de Rennes 1-CNRS, 35042 Rennes, France, +332 2323 5748),

\section{Highlights}

- Optical chloroform detection

- $\operatorname{Pr}^{3+}$ doped chalcogenide fibers

- Tapered optical fibers

- Pr: GaGeSbS spectroscopy

- Mid-IR incoherent emission sources 


\begin{abstract}
Chalcogenide glasses, owing to their transparency in the infrared window and the appropriate solubility of rare earth, allows the generation of middle infrared (mid-IR) radiation from a near infrared or visible pumping source. These emitted mid-IR broad bands can probe the vibrational modes of several molecules, e.g. $\mathrm{C}-\mathrm{H}, \mathrm{C}=\mathrm{O}$ or $\mathrm{C}-\mathrm{Cl}$. Relying on this principle, a mid-IR optical sensor using the mid-IR fluorescence of $\operatorname{Pr}^{3+}$ : Ga-Ge-Sb-S fibers has been developed. The detection principle is based on Fiber Evanescent Wave Spectroscopy (FEWS). The spectroscopic characterization of praseodymium ions $\left(\mathrm{Pr}^{3+}\right)$ was performed in the near and mid-IR and is discussed on the basis of comparison with Judd-Ofelt calculations. The broad emission spectrum of the $\operatorname{Pr}^{3+}$ : Ga-Ge-Sb-S fiber from 4 to $5 \mu \mathrm{m}$ could enable the monitoring of multiple pollutants. In this study, chloroform detection is carried out via a novel technique derived from FEWS. In this way, an infrared sensor was developed, composed of a pumping source in near-IR, a mid-IR detector and a tapered $\operatorname{Pr}^{3+}$ : chalcogenide fiber to enhance the detection sensitivity. These results demonstrate for the first time the feasibility of detecting molecules by FEWS using the mid-IR fluorescence emitted by rare earth ions doping chalcogenide fibers. This method is an effective alternative to the classical FEWS system, as RE doped chalcogenide fibers have the advantage of being a compact mid-IR source.
\end{abstract}

\title{
Keywords:
}

chalcogenide glasses, fibers, FEWS; praseodymium, mid-IR optical sensor, chloroform 


\section{Introduction}

A wide range of (bio)-chemical molecules have vibrational modes in the fingerprint region localized in the middle infrared (mid-IR) spectral range. Thus, the detection of such species using their strong absorption bands in mid-IR could be achieved using a dedicated optical sensor. Chalcogenide fibers based on sulfur, selenium, or tellurium enable the propagation of an infrared optical signal and enable the absorption bands of (bio)-chemical species to be collected. Indeed, these materials present a large optical window extending in the mid-IR and covering the two atmospheric windows ranging from 3 to 5 and 8 to $12 \mu \mathrm{m}$. Fiber Evanescent Wave Spectroscopy (FEWS) simply requires dipping the fiber into the liquid under analysis or putting it in direct contact with the analyte. FEWS using chalcogenide glass fibers is an efficient tool and the chalcogenide fibers can be specifically shaped for head sensing thanks to the fibers' thermo-forming capability [1]. It also allows investigation in different fields; e.g. the detection of pollutants in waste water $[2,3]$, the monitoring of chemical or industrial processes $[4,5]$, the detection of bacterial contamination in food $[6,7]$, and applications in the medical field [8]. Consequently, these materials can contribute to the development of pioneering glass technologies in IR spectral windows to design innovative optical sensors.

In addition to these specific characteristics in the passive optical mode, chalcogenide glasses can provide valuable emissions in mid-IR [9-13]. Their low phonon energy enables them to be transparent up to $20 \mu \mathrm{m}$ in the case of telluride based materials, and rare earth ions can be efficiently incorporated into the chalcogenide host matrix. In the case of fluoride materials, the phonon energy is not low enough to generate wavelength lasing or even luminescence further than $3 \mu \mathrm{m}$. The rare earth transitions are easily quenched between two relatively close energy levels involved in the IR emission processes. For the 3-5 $\mu \mathrm{m}$ domain, 
sulfide and selenide materials are quite suitable materials for use in optical fiber detectors, as the fiber drawing processes from theses RE doped preforms is well mastered [10-15].

An optical sensor based on mid-IR fluorescence to probe gas molecules has already been developed using a transmission configuration instead of FEWS for the detection of carbon dioxide by means of the $4.3 \mu \mathrm{m}$ emission of a $\mathrm{Dy}^{3+}$ doped chalcogenide fiber [16]. Due to their high degree of mechanical integration and reliability (connectors, fiber coating techniques), optical fiber-based sensors are designed for commercial purposes. Compared to FEWS using undoped chalcogenide fibers as the sensitive media, this sensor has been developed in order to produce its own mid-IR fluorescence source. The resolution of real time detection could be enhanced and the overall compactness and complexity of the optical system can be efficiently reduced. FEWS relies on the optical absorption of the surrounding environment of the optical fiber, with a typical penetration depth of a few micrometers for the evanescent waves. The degree of integration of such devices is potentially high thanks to the rare earth doped chalcogenide fiber converting the pump signal from a visible or near infrared laser diode to mid-IR. By means of frequency conversion, the sensor could allow remote monitoring using silica fibers considering that the inverse photon conversion from mid-IR to visible or near-IR can be used based on a rare earth up-conversion phenomenon [17].

\section{Materials and methods}

\section{1. $\mathrm{Pr}^{3+}: \mathrm{Ga}_{5} \mathrm{Ge}_{25} \mathrm{Sb}_{10} \mathrm{~S}_{65}$ bulk glass, fiber and taper fabrication}

The composition of sulfide glass is $\mathrm{Ga}_{5} \mathrm{Ge}_{20} \mathrm{Sb}_{10} \mathrm{~S}_{65}$ doped with 500, 1000 and $3000 \mathrm{ppm}$ $\operatorname{Pr}^{3+}$ ion concentrations. These glasses were prepared using conventional melting and quenching methods. Ga, Ge, Sb and $\mathrm{S}$ with high purity $(\geq 5 \mathrm{~N})$ and praseodymium sulfide with $3 \mathrm{~N}$ purity were used. Commercial sulfur was purified by successive distillations to remove 
carbon $\left(\mathrm{CO}_{2}, \mathrm{CS}_{2}, \mathrm{COS}\right)$, hydrate, or sulfide hydride $\left(\mathrm{H}_{2} \mathrm{O}, \mathrm{OH}, \mathrm{SH}\right)$ impurities [18]. Then, chemical reagents were put in silica tubes and pumped under vacuum $\left(10^{-4} \mathrm{mbar}\right)$. After sealing, the chemical reagents were melted under slow heating to $850^{\circ} \mathrm{C}$ for 10 hours in a rocking furnace to ensure homogenization. The ampoule was quenched in water, then annealed at $280^{\circ} \mathrm{C}$ for 3 hours. Single index fibers with a $350 \mu \mathrm{m}$ diameter were obtained by drawing $7 \mathrm{~mm}$ diameter and $100 \mathrm{~mm}$ length $\mathrm{Pr}^{3+}$-doped $\mathrm{Ga}_{5} \mathrm{Ge}_{20} \mathrm{Sb}_{10} \mathrm{~S}_{65}$ preforms. Tapers were obtained by heating the fiber locally and slowly stretching it. To perform the optical and spectroscopic characterizations, bulk glass slices were cut and polished.

\section{2. $\operatorname{Pr}^{3+}$ : GaGeSbS spectroscopic properties}

$\operatorname{Pr}^{3+}: \mathrm{Ga}_{5} \mathrm{Ge}_{20} \mathrm{Sb}_{10} \mathrm{~S}_{65}$ absorption spectra were recorded using a Perkin-Elmer Lambda 1050 and a Bruker FTIR Tensor 37 spectrophotometer for the near-IR and the mid-IR spectral domains, respectively. Fluorescence spectra were recorded using two pumping sources: a Lumics LU1470-T015 laser diode tuned at $1490 \mathrm{~nm}$ and a homemade Tm: YAG laser emitting at $2.0 \mu \mathrm{m}$. These two sources were used to investigate emission spectrum shape differences from one pumping wavelength to another [19]. The luminescence signal was collected using a nitrogen cooled InSb detector, a lock-in amplifier, and a monochromator with a resolution of $25 \mathrm{~nm}$. The lock-in amplifier integration time was $1 \mathrm{~s}$ with a $35 \mathrm{~Hz}$ chopping frequency. The spectral response of the whole acquisition device was wavelengthdependent; emission spectra were calibrated using a tungsten-halogen lamp source and a heat source with emission spectra similar to a black-body source. Therefore, to record fluorescence signals without any parasitic absorption, such as carbon dioxide at $4.25 \mu \mathrm{m}$, the monochromator was flushed with dry nitrogen.

The incident power on bulk samples and fiber input was $800 \mathrm{~mW}$. For lifetime measurements, a Continuum Horizon OPO laser delivering $5 \mathrm{~ns}$ pulses at a repetition rate of 
$10 \mathrm{~Hz}$ was used for the optical excitation. The signal was imaged on the InSb detector using a lens and passed through $2.36 \mu \mathrm{m}, 4.00 \mu \mathrm{m}$ and $4.64 \mu \mathrm{m}$ centered band-pass filters respectively.

\subsection{Fluorescent FEWS optical sensor}

The $\operatorname{Pr}^{3+}$ : Ga5 $\mathrm{Ge}_{20} \mathrm{Sb}_{10} \mathrm{~S}_{65}$ fiber was pumped using a homemade Tm: YAG laser emitting at $2.0 \mu \mathrm{m}$ pumped by a Ti: Sapphire laser tuned at $780 \mathrm{~nm}$. The beam was focalized on the fiber using a first lens, and the output was imaged on the monochromator entrance slit using a second $\mathrm{CaF}_{2}$ optics (Figure 8). To deduce the chloroform absorption from the emission spectra of the doped fiber, the emission signal obtained through an air flushed cell is used as the reference line. Two spectra with and without chloroform were then recorded, which gave the $I_{\text {diff }}(\lambda)$ curve as a function of the wavelength (eq.1).

$$
I_{\text {diff }}(\lambda)=\frac{I_{(\text {empty cell })}-I_{\left(\mathrm{CHCl}_{3}\right)}}{I_{(\text {empty cell })}}(\text { eq. } 1)
$$

These Idiff $(\lambda)$ curves were then investigated as a function of the geometrical parameters of the taper. The signal was collected in a nitrogen cooled InSb detector.

\section{Results and discussion}

\section{1. $\mathrm{Pr}^{3+}:$ GaGeSbS spectroscopic properties}

\subsubsection{Absorption and Judd-Ofelt calculations}

The room temperature absorption cross-section spectrum of a $1000 \mathrm{ppm}$ doped $\operatorname{Pr}^{3+}$ : $\mathrm{Ga}_{5} \mathrm{Ge}_{20} \mathrm{Sb}_{10} \mathrm{~S}_{65}$ glass is presented in Figure 1-A. The $\mathrm{Pr}^{3+}$ GaGeSbS glass shows overlapped of the ${ }^{3} \mathrm{~F}_{4}(1580 \mathrm{~nm}),{ }^{3} \mathrm{~F}_{3}(1475 \mathrm{~nm}),{ }^{3} \mathrm{~F}_{2}(2020 \mathrm{~nm})$ and ${ }^{3} \mathrm{H}_{6}(2250 \mathrm{~nm})$ absorption bands. At a wavelength of $1020 \mathrm{~nm}$, the weak ${ }^{1} \mathrm{G}_{4}$ absorption band could be identified. The infrared absorption cross-section between the fundamental ${ }^{3} \mathrm{H}_{4}$ and the first excited ${ }^{3} \mathrm{H}_{5}$ manifolds is presented in Figure 1-B. These absorption cross-sections feature peak values comparable to 
other sulfide praseodymium doped materials [20]. In Figure 1-B, the emission band was calculated using the cross section reciprocity properties, as formulated by McCumber [21, 22]. The corresponding zero-line phonon energy was $2178 \mathrm{~cm}^{-1}$.

Before performing the Judd-Ofelt analysis, the overlapped contributions had to be isolated by means of a pseudo-Voigt fit [23]. The mid-IR absorption band corresponding to the ${ }^{3} \mathrm{H}_{4} \rightarrow{ }^{3} \mathrm{H}_{5}$ transition extended from 3.8 to over $5.2 \mu \mathrm{m}$ (Figure 1-B), indicating that the ${ }^{3} \mathrm{H}_{5}$ manifold Stark splitting was leading to a broad absorption level. From these integrated absorption bands, a Judd-Ofelt analysis was performed to estimate the emitting manifold lifetimes and branching ratios $[24,25]$. Using a standard method of least squares adjustment, the calculated $\Omega_{2,4,6}$ parameters were $10.3 ; 2.6 ; 8.0 \times 10^{-20} \mathrm{~cm}^{2}$, which is in good agreement with some other works [26]. The calculated manifold lifetimes were compared to the experimental values, as shown in Table 1.

In the following section, this comparison will be discussed in relation to some glass matrix effects, e.g. multiphonon relaxation rates and cross-relaxation processes. Even if the Judd-Ofelt calculation requires some approximation and its results should usually be considered with care, a huge discrepancy between the measured and the calculated values clearly indicates that another relaxation process occurs, invalidating the isolated ion case.

\subsubsection{Emission properties}

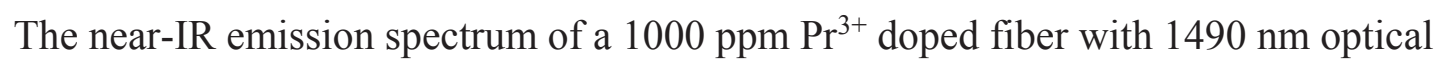
pumping is shown in Figure 2. The full width at half maximum (FWHM) of the emission band is about $250 \mathrm{~nm}$, and is mainly composed of two major contributions from the ${ }^{3} \mathrm{~F}_{3} \rightarrow{ }^{3} \mathrm{H}_{5}$ and ${ }^{3} \mathrm{H}_{6} \rightarrow{ }^{3} \mathrm{H}_{4}$ transitions (Figure 2 inset and Table 1). The observation of simultaneous emissions from the $\left({ }^{3} \mathrm{~F}_{2},{ }^{3} \mathrm{H}_{6}\right)$ and $\left({ }^{3} \mathrm{~F}_{4},{ }^{3} \mathrm{~F}_{3}\right)$ manifolds is possible due to multiphonon relaxation rate being in the same order of magnitude as the radiative process rate. Considering the phonon energy of the germanium sulfide glass matrix $\left(\sim 340-430 \mathrm{~cm}^{-1}\right)$, approximately 
three to four phonons are required to bridge the energy gap between the ${ }^{3} \mathrm{~F}_{3} \rightarrow{ }^{3} \mathrm{~F}_{2}$ levels $\left(\approx 1300 \mathrm{~cm}^{-1}\right)$.

For the $\left({ }^{3} \mathrm{~F}_{2},{ }^{3} \mathrm{H}_{6}\right)$ manifold, the luminescence is mainly due to the ${ }^{3} \mathrm{H}_{6} \rightarrow{ }^{3} \mathrm{H}_{4}$ transition. Some reciprocity calculations separately performed on the ${ }^{3} \mathrm{H}_{6}$ and ${ }^{3} \mathrm{~F}_{2}$ absorption bands showed that the calculated ${ }^{3} \mathrm{H}_{6} \rightarrow{ }^{3} \mathrm{H}_{4}$ emission band matches the experimental data. The focus is on the mid-IR emission band, which is of interest for the above mentioned applicative purposes. Some investigations were performed regarding the influence of pumping wavelength, fiber drawing, and fiber length on the shape of the emission bands (Figure 3).

According to the absorption data and reciprocity calculations, the expected emission bands are in a good agreement with Park et al. for selenide materials [16(Par08)]. This broad mid-IR emission band is composed of the $\left({ }^{3} \mathrm{~F}_{2},{ }^{3} \mathrm{H}_{6}\right) \rightarrow{ }^{3} \mathrm{H}_{5}(3.5-4.2 \mu \mathrm{m})$ and ${ }^{3} \mathrm{H}_{5} \rightarrow{ }^{3} \mathrm{H}_{4}(4.0$ $-5.5 \mu \mathrm{m})$ transitions, the structures of which are similar to those found in some other studies $[14,19]$. In Figure 1-B, the emission line was calculated using the cross-section reciprocity properties, as formulated by McCumber [21, 22]. The calculated emission cross-section shows a maximum at a wavelength of $4750 \mathrm{~nm}$, which is also the case in the experimental bulk glass emission spectrum (Figure 3), indicating that the fluorescence contributions above a wavelength of $4.5 \mu \mathrm{m}$ are due to the ${ }^{3} \mathrm{H}_{5} \rightarrow{ }^{3} \mathrm{H}_{4}$ contribution.

The differences between the band shapes of the spectra arising from the pumping of the ${ }^{3} \mathrm{~F}_{2}$ and $\left({ }^{3} \mathrm{~F}_{3},{ }^{3} \mathrm{~F}_{4}\right)$ manifolds were first studied (Figure 3-A). Few intensity variations could be noted at $4.5 \mu \mathrm{m}$ on $500 \mathrm{ppm}$ doped bulk glass for the two pumping wavelengths of $1.49 \mu \mathrm{m}$ and $1.5 \mu \mathrm{m}$; however, the spectra remain quite similar. In the sulfide glasses, no modification in the emission band shape comparable to that reported by Park et al. in $\operatorname{Pr}^{3+}$ : GaGeSbSe glass [14] was observed. In $\operatorname{Pr}^{3+}$ : GaGeSbS glass, a strong contribution arises at $5.25 \mu \mathrm{m}$ with 2.0 $\mu \mathrm{m}$ pumping, which is not the case with a $1.5 \mu \mathrm{m}$ pumping scheme. 
Figure 3-B shows the comparison between the spectrum produced by a $92 \mathrm{~mm}$ long fiber and the corresponding bulk glass emission spectrum, and some remarkable differences are noticeable. Due to the length of the fiber relative to the optical path length available in bulk glass, the S-H and C-S absorption bands are more noticeable at 4.0 and $4.9 \mu \mathrm{m}$, respectively, on the fiber emission spectrum than on the bulk emission spectrum. Some amplified spontaneous emissions and reabsorption occurs along the propagation in the fiber, locally enhancing some contributions (4.8 and $5.0 \mu \mathrm{m}$ for instance). In the fiber emission spectrum, the third order of the pump is not visible due to efficient pump absorption. The fiber length also has an impact on the emission band shape, allowing a level of reabsorption, amplified spontaneous emission (ASE), and impurity quenching processes. Some non-normalized emission spectra from fluorescence cut-back experiments for $500 \mathrm{ppm}^{\mathrm{Pr}^{3+}}$ doped fibers are shown in Figure 4.

In Figure 4, for fiber lengths of about $10 \mathrm{~cm}$ (81 and $137 \mathrm{~mm}$ presented here), the emission intensities are quite comparable, indicating that the optimum length for this $500 \mathrm{ppm}$ doped fiber mid-IR emission band is about $10 \mathrm{~cm}$. The $179 \mathrm{~mm}$ long fiber 4.25-5.0 $\mu \mathrm{m}$ luminescence is affected by strong ${ }^{3} \mathrm{H}_{4} \rightarrow{ }^{3} \mathrm{H}_{5}$ reabsorption, which is a consequence of the previous pump absorption.

S-H and C-S impurity absorption bands are logically slightly more visible on the 179 $\mathrm{mm}$ long fiber emission spectrum. These trends are also noted for $1000 \mathrm{ppm}$ doped fibers, with an optimum length of about $7 \mathrm{~cm}$.

\subsubsection{Lifetimes}

The experimental lifetimes were measured at room temperature. Figure 5 shows the lifetimes of the $\left({ }^{3} \mathrm{~F}_{4},{ }^{3} \mathrm{~F}_{3}\right),\left({ }^{3} \mathrm{~F}_{2},{ }^{3} \mathrm{H}_{6}\right)$ and ${ }^{3} \mathrm{H}_{5}$ manifolds with pumping at $1650 \mathrm{~nm}\left({ }^{3} \mathrm{~F}_{4}\right) .2 .36 \pm$ $0.40 \mu \mathrm{m}, 4.00 \pm 0.40 \mu \mathrm{m}$ and $4.64 \pm 0.40 \mu \mathrm{m}$ filters were used to isolate the ${ }^{3} \mathrm{~F}_{4}{ }^{3} \mathrm{~F}_{3} \rightarrow{ }^{3} \mathrm{H}_{5}$, 
$\left({ }^{3} \mathrm{~F}_{2}{ }^{3} \mathrm{H}_{6}\right) \rightarrow{ }^{3} \mathrm{H}_{5}$, and the ${ }^{3} \mathrm{H}_{5} \rightarrow{ }^{3} \mathrm{H}_{4}$ transitions, respectively. The transmission width of these filters ensures the selective lifetime measurement of the two different contributions [14].

For the experimental fluorescence lifetime, the usual trend of faster decay as the $\operatorname{Pr}^{3+}$ concentration increases was observed. The $500 \mathrm{ppm}$ doped glass experimental lifetime was then compared to the Judd-Ofelt calculations. For the ${ }^{3} \mathrm{~F}_{3} \rightarrow{ }^{3} \mathrm{H}_{5}$ transition, the calculated lifetime is about $400 \mu \mathrm{s}$, and the experimental lifetime was $109 \mu$ s. Considering that the JuddOfelt theory does not take into account any energy transfers, including luminescence quenching due to impurities, reasonable agreement remains between the calculated and measured values. The fluorescence lifetimes of the levels involved in transitions with lower energy differences witness an intense quenching process. The experimental lifetime for the $\left({ }^{3} \mathrm{~F}_{2},{ }^{3} \mathrm{H}_{6}\right) \rightarrow{ }^{3} \mathrm{H}_{5}$ transition was shorter by more than an order of magnitude than the calculated value, and the same was true for the ${ }^{3} \mathrm{H}_{5} \rightarrow{ }^{3} \mathrm{H}_{4}$ transition, where the calculated lifetimes were respectively 8.2 and $15.9 \mathrm{~ms}$ and the experimental values were some hundreds of microseconds.

In other studies using selenide glasses, the measured lifetimes were much closer to the calculated values [14], such as $11.5 \mathrm{~ms}$ for the ${ }^{3} \mathrm{H}_{5} \rightarrow{ }^{3} \mathrm{H}_{4}$ transition for Pr: GeAsGaSe glass [11]. This indicates that a strong quenching effect seems to occur in sulfide glasses. This could be explained by the S-H bonds $(4.0 \mu \mathrm{m})$, whose resonance belongs to the same spectral domain as the $\operatorname{Pr}^{3+}$ emission, and also the $\mathrm{S}-\mathrm{C}$ bond (at $4.9 \mu \mathrm{m}$ ). Absorption analysis of the glass preforms showed a low concentration at around $30 \mathrm{ppm}$ for [SH] species. As also observed for other rare earth ions, this matrix could lead to some rare earth clustering, which could promote the quenching of luminescence and also contribute to a drop in fluorescence lifetime. This spectroscopic analysis of lifetimes allowed us to identify the necessary means to 
develop a glass preform synthesis to improve the efficiency of the $\operatorname{Pr}^{3+}$ : sulfide mid-IR sources.

\subsection{FEWS experimentations}

The sensor is essentially composed of a tapered doped fiber hermetically mounted into a glass cell containing chloroform (Figure 6).

The detection experiments were performed by pouring chloroform into the glass cell and comparing the fiber emission spectra recorded with those obtained without chloroform. As already mentioned in the introduction, for FEWS detection, chalcogenide fibers have already proved to be suitable materials. This technique is based upon the evanescent field attenuation caused by the absorption of the surrounding media and related to the Goos-Hänchen shift in the case of total internal reflections. The evanescent field penetration depth is a function of the refractive index contrast between the analyte and the fiber [27]. For a $\mathrm{Ga}_{5} \mathrm{Ge}_{20} \mathrm{Sb}_{10} \mathrm{~S}_{65}$ fiber, the evanescent field penetration depth is about $1 \mu \mathrm{m}$ for a wavelength in the 2-12 $\mu \mathrm{m}$ range. Previous experiments show that this value is sufficient to achieve a useful level of sensitivity for a passive optical fiber [3, 28, 29]. In this study, the fluorescence of the rare earth incorporated in the fiber generated the probing signal, instead of a more expensive and less compact mid-IR laser source.

To enhance the sensitivity of a FEWS sensor, the number of total internal reflections per unit length should be maximized, which is the aim of the tapered fiber [29, 30]. The thinner the taper is, the larger the number of total internal reflections that occur per length unit, therefore making the detection more sensitive. The slopes between $\Phi 1$ and $\Phi 2$ should not be too steep in order to minimize the optical losses of the infrared beam during the change in diameter (Figure 7). 
For these tapers, the conical shape spreads over a length of about $1 \mathrm{~cm}$ for a $350 \mu \mathrm{m}$ single index fiber tapered to diameters ranging from 80 to $40 \mu \mathrm{m}$. In our study, a $350 \mu \mathrm{m}$ diameter was maintained at the input and output of the taper to ensure an efficient pumping beam injection for pumping powers at about $1 \mathrm{~W}$. The experimental setup is shown in Figure 8. The $\mathrm{CHCl}_{3}$ infrared absorption spectrum was also recorded using an FTIR spectrophotometer with a sealed cell with $\mathrm{CaF}_{2}$ windows (Figure 9).

Chloroform possesses four main absorption bands corresponding to the stretching and bending modes of $\mathrm{C}-\mathrm{H}$ and $\mathrm{C}-\mathrm{Cl}$ bonds. Alongside these bands are some harmonic frequencies of lower intensity, like the band observed at $4.16 \mu \mathrm{m}$. Figure 9-B shows the liquid chloroform absorption spectrum versus the Pr: GaGeSbS mid-IR fluorescence signal. The $\mathrm{CHCl}_{3}$ absorption band with a moderate absorption cross-section at $4.1 \mu \mathrm{m}$ is overlapped by the $\operatorname{Pr}^{3+}$ emission generated by both ${ }^{3} \mathrm{H}_{6} \rightarrow{ }^{3} \mathrm{H}_{5}$ and ${ }^{3} \mathrm{H}_{5} \rightarrow{ }^{3} \mathrm{H}_{4}$ transitions, and suggest that chloroform detection could be implemented by the fluorescent FEWS technique. Apart from the feasibility of $\mathrm{CHCl}_{3}$ detection using a $\mathrm{Pr}^{3+}$ doped chalcogenide fiber, the taper diameter effect on the absorption of the evanescent field and the effect of the rare earth concentration were studied.

The absorbed signal was higher with a tapered fiber, and could hardly be measured with $500 \mathrm{ppm} \operatorname{Pr}^{3+}: \mathrm{GaGeSbS}$ with a $350 \mu \mathrm{m}$ core diameter. This absorption could not even be observed with a 1000 ppm doped fiber.

In a simplified geometrical approach, the reduction of taper diameter involves more reflections of light at the interface between the fiber and the chloroform, so that the evanescent wave is in greater contact with the absorbing solution, leading to more efficient sensing (Figure 7). For the 1000 ppm doped fiber, this enhancement was clearly visible, but this gain was more obvious on the 500 ppm doped fiber. The highest absorption signal was measured for a $40 \mu \mathrm{m}$ tapered $500 \mathrm{ppm}$ doped sulfide fiber. 


\section{Conclusion}

During this work, fibers were successfully drawn from Pr: GaGeSbS preforms, and the mid-IR spectroscopic properties (absorption, emission, and lifetimes) of both bulk glass and the fibers were investigated as a function of the doping rate. Judd-Ofelt calculations were also performed.

For $350 \mu \mathrm{m}$ initial diameter rare earth doped fibers, 80 to $40 \mu \mathrm{m}$ tapers were fabricated. This tapered fiber was then optically pumped, and this embedded mid-IR source was used to perform FEWS experiments. Praseodymium doped fibers were used to detect the chloroform $\left(\mathrm{CHCl}_{3}\right) 4160 \mathrm{~nm}$ absorption band. For the first time, the detection of a pollutant was performed by the FEWS method using rare earth luminescence; more generally, this paper shows the possibility of using rare earth doped chalcogenide fibers in sensors. The use of the broad emission band of $\mathrm{Pr}^{3+}$ to detect $\mathrm{CHCl}_{3}$ is witness to the fact that this particular fiber is able to detect several species having fingerprints in the 3-5 $\mu \mathrm{m}$ spectral range. On this basis, a dedicated sensor could be fabricated using a $4.1 \mu \mathrm{m}$ centered band-pass filter, combined with a monitoring application controlling both the laser diode source and a reference arm to enable differential detection.

\section{Acknowledgements:}

This work was supported by the French Environment and Energy Management Agency (ADEME). 


\section{References}

[1] P. Houizot, M.L. Anne, C. Boussard-Pledel, O. Loreal, H. Tariel, J. Lucas, et al., Shaping of Looped Miniaturized Chalcogenide Fiber Sensing Heads for Mid-Infrared Sensing, Sensors, 14(2014) 17905-14.

[2] K. Michel, B. Bureau, C. Boussard-Pledel, T. Jouan, J.L. Adam, K. Staubmann, et al., Monitoring of pollutant in waste water by infrared spectroscopy using chalcogenide glass optical fibers, Sensors and Actuators B-Chemical, 101(2004) 252-9.

[3] J.S. Sanghera, F.H. Kung, L.E. Busse, P.C. Pureza, I.D. Aggarwal, Infrared evanescent absorption-spectroscopy of toxic-chemicals using chalcogenide class fibers, J Am Ceram Soc, 78(1995) 2198-202.

[4] D. Le Coq, K. Michel, J. Keirsse, C. Boussard-Pledel, G. Fonteneaua, B. Bureau, et al., Infrared glass fibers for in-situ sensing, chemical and biochemical reactions, C R Chim, 5(2002) 907-13.

[5] M.L. Anne, E.L.G. La Salle, B. Bureau, J. Tristant, F. Brochot, C. Boussard-Pledel, et al., Polymerisation of an industrial resin monitored by infrared fiber evanescent wave spectroscopy, Sensors and Actuators B-Chemical, 137(2009) 687-91.

[6] M.L. Brandily, V. Monbet, B. Bureau, C. Boussard-Pledel, O. Loreal, J.L. Adam, et al., Identification of foodborne pathogens within food matrices by IR spectroscopy, Sensors and Actuators B-Chemical, 160(2011) 202-6.

[7] X. Jiang, A. Jha, Engineering of a Ge-Te-Se glass fibre evanescent wave spectroscopic (FEWS) mid-IR chemical sensor for the analysis of food and pharmaceutical products, Sensors and Actuators B-Chemical, 206(2015) 159-69.

[8] M.L. Anne, C. Le Lan, V. Monbet, C. Boussard-Pledel, M. Ropert, O. Sire, et al., Fiber evanescent wave spectroscopy using the mid-infrared provides useful fingerprints for metabolic profiling in humans, J Biomed Opt, 14(2009).

[9] J.S. Sanghera, L.B. Shaw, I.D. Aggarwal, Chalcogenide Glass-Fiber-Based Mid-IR Sources and Applications, IEEE J Sel Top Quantum Electron, 15(2009) 114-9.

[10] B.J. Park, H.S. Seo, J.T. Ahn, Y.G. Choi, J. Heo, W.J. Chung, Dy(3+) doped Ge-Ga-SbSe glasses and optical fibers for the mid-IR gain media, J Ceram Soc Jpn, 116(2008) 1087-91. [11] L. Sojka, Z. Tang, D. Furniss, H. Sakr, A. Oladeji, E. Beres-Pawlik, et al., Broadband, mid-infrared emission from $\operatorname{Pr}(3+)$ doped GeAsGaSe chalcogenide fiber, optically clad, Optical Materials, 36(2014) 1076-82.

[12] V. Moizan, Nazabal,V., Troles, J., Houizot, P., Adam, J.-L., Smektala, F., Gadret,G., Pitois, S., Doualan, J.-L., Moncorgé,R., Canat, G., Er3+-doped GeGaSbS glasses for mid-IR fibre laser application: Synthesis and rare earth spectroscopy, Optical Material, 31(2008) 3946.

[13] F. Charpentier, F. Starecki, J.L. Doualan, P. Jovari, P. Camy, J. Troles, et al., Mid-IR luminescence of Dy3+ and Pr3+ doped Ga5Ge20Sb10S(Se)(65) bulk glasses and fibers, Mater Lett, 101(2013) 21-4.

[14] B.J. Park, H.S. Seo, J.T. Ahn, Y.G. Choi, D.Y. Jeon, W.J. Chung, Mid-infrared (3.5-5.5 mu m) spectroscopic properties of Pr3+-doped Ge-Ga-Sb-Se glasses and optical fibers, $\mathrm{J}$ Lumin, 128(2008) 1617-22.

[15] S. Cui, R. Chahal, C. Boussard-Pledel, V. Nazabal, J.L. Doualan, J. Troles, et al., From Selenium-to Tellurium-Based Glass Optical Fibers for Infrared Spectroscopies, Molecules, 18(2013) 5373-88.

[16] F. Starecki, F. Charpentier, J.L. Doualan, L. Quetel, K. Michel, R. Chahal, et al., Mid-IR optical sensor for $\mathrm{CO} 2$ detection based on fluorescence absorbance of

Dy3+:Ga5Ge20Sb10S65 fibers, Sensors and Actuators B-Chemical, 207(2015) 518-25. 
[17] A.L. Pelé, A. Braud, J.L. Doualan, R. Chahal, V. Nazabal, C. Boussard-Plédel, et al., Wavelength conversion in Er3+ doped chalcogenide fibers for optical gas sensors, Opt Express, 23(2015) 4163-72.

[18] V. Moizan, V. Nazabal, J. Troles, P. Houizot, J.L. Adam, J.L. Doualan, et al., Er3+doped GeGaSbS glasses for mid-IR fibre laser application: Synthesis and rare earth spectroscopy, Optical Materials, 31(2008) 39-46.

[19] L.B. Shaw, Cole, B., Thielen, P. A., Sanghera, J. S., Aggarwal, I. D. , Mid-wave IR and long-wave IR laser potential of rare-earth doped chalcogenide glass fiber, IEEE J Quantum Electron, 37(2001) 1127-37.

[20] A. Nistreanu, N. Enachi, M. Iovu, V. Koroli, D. Furniss, A. Seddon, The spontaneous emission probabilities for Ga-La-S:Pr(3+) glass, Journal of Optoelectronics and Advanced Materials, 12(2010) 800-5.

[21] D.E. McCumber, Einstein relations connecting broadband emission + absorption spectra, Physical Review a-General Physics, 136(1964) A954-\&.

[22] R.S. Quimby, R. earth, Range of validity of McCumber theory in relating absorption and emission cross sections, J Appl Phys, 92(2002) 180-7.

[23] M. Olivier, J.L. Doualan, V. Nazabal, P. Camy, J.L. Adam, Spectroscopic study and Judd-Ofelt analysis of Pr3+-doped Zr-Ba-La-Al glasses in visible spectral range, Journal of the Optical Society of America B-Optical Physics, 30(2013) 2032-42.

[24] B.R. Judd, Optical Absorption Intensities of Rare-Earth Ions, Phys Rev A, 127(1962) 750.

[25] G.S. Ofelt, Intensities of Crystal Spectra of Rare-Earth Ions, The Journal of Chemical Physics, 37(1962) 511-20.

[26] K. Wei, D.P. Machewirth, J. Wenzel, E. Snitzer, G.H. Sigel, Pr3+-doped ge-ga-s glasses for 1.3-mu-m optical-fiber amplifiers, J Non-Cryst Solids, 182(1995) 257-61.

[27] N.J. Harrick, Internal reflection spectroscopy, Harrick Scientific Corporation NY, John Wiley \& Sons Inc1967.

[28] H. Steiner, M. Jakusch, M. Kraft, M. Karlowatz, T. Baumann, R. Niessner, et al., In situ sensing of volatile organic compounds in groundwater: First field tests of a mid-infrared fiberoptic sensing system, Appl Spectrosc, 57(2003) 607-13.

[29] M. Katz, A. Katzir, I. Schnitzer, A. Bornstein, Quantitative-evaluation of chalcogenide glass-fiber evanescent-wave spectroscopy, Appl Opt, 33(1994) 5888-94.

[30] S. Hocde, C. Boussard-Pledel, G. Fonteneau, D. Lecoq, H.L. Ma, J. Lucas, Recent developments in chemical sensing using infrared glass fibers, J Non-Cryst Solids, 274(2000) $17-22$. 


\section{Biographies}

R. Chahal is a PhD student at the Chemical Sciences Institute (ISCR) at the University of Rennes, France. The subject of his thesis, supervised by Prof. Bruno Bureau and Dr. Virginie Nazabal, is devoted to the development of mid-IR optical sensors based on chalcogenide glasses applied for detection and monitoring of $\mathrm{CO}_{2}$.

Dr. F. Starecki received his Ph.D. degree from the University of Caen, France, in 2013. This work was focused on visible and near-infrared laser emitting waveguides, grown by the liquid phase epitaxy technique (LPE). Now working as a post-doctoral associate at the Chemical Sciences Institute (ISCR) on supercrictical $\mathrm{CO}_{2}$ optical detection embedded in microreactors.

Dr. Catherine Boussard-Pledel, defended her PhD, focused on glasses in the system B-O-F, at the University of Rennes (France) in 1997. Since 1999, she is engineer of research at the CNRS, in the Glasses and Ceramics group at ISCR in Rennes. She is in charge of the development of fibers (multimode, single mode) and she works on the development of infrared sensors having applications in biomedicine, environment and spatial areas. She is involved in several international research programs. She is the author and co-author of about 100 publications and several patents.

Dr. J.-L. Doualan is CNRS researcher in the group MIL of the CIMAP laboratory. He has got the Doctorat es Sciences Physiques degree in 1988, on the study of colour center lasers, his research interest then turned to the fabrication, the spectroscopy and the laser applications of the rare earth doped laser materials. He is currently working on Mid-IR sensors based on rare earth doped chalcogenide fibers for detection of specific chemical species. He has been an author or a co-author of more than 200 articles and four patents. 
Dr. K. Michel is a scientific researcher at BRGM. She holds a $\mathrm{PhD}$ in Chemistry from University of Rennes. Her thesis is entitled "Infrared fiber optical sensor dedicated to detection of water pollution". She has been involved on $\mathrm{CO}_{2}$ storage since the Weyburn, Geocarbone monitoring, Sentinelle, Optique $\mathrm{CO}_{2}$ projects. She participates to various European and national $\mathrm{CO}_{2}$ storage projects, including $\mathrm{CO}_{2} \mathrm{GeoNet}$. Her key qualifications are: chemistry, soil gas, monitoring, sensors and mineral characterization.

Dr. L. Brilland is an engineer of research at PERFOS Company. He is specialist of chalcogenide microstructured fibers fabrication and author and co-authors of more than 40 publications.

Dr. A. Braud is Associate Professor at the University of CAEN (France). He received his $\mathrm{PhD}$ in Physics in 1999. He was a Post-doc at Montana State University (Bozeman, Montana, USA) and worked after as a Research Contractor at NASA Langley Research Center (USA) developing high power lasers for LIDAR applications. In 2008, he was a visiting Professor at Boston College, USA. A.Braud's research concentrates on rare earth and transition metal doped materials for laser, lighting and photovoltaic applications. He is author and co-author of two chapter books and more than 50 papers in scientific journals with referees.

Pr. P. Camy received the Master degree from the Institut d'Optique in Paris in 1993 and the Doctorate degree in Physics at the University of Pierre et Marie Curie (Paris) in 1996. He is now full professor at the University of Caen, assistant director of the CIMAP laboratory and team leader of the group "Matériaux et Instrumentation Laser". He is involved in projects concerning rare earth doped materials for lasers and sensors applications. He is author or coauthor of more than 80 articles in scientific journals, co-inventor of 4 patents and Associate Editor for Optics Express Journal of the OSA. 
Pr. B. Bureau, PhD, "Local order investigations in fluoride glasses by multinuclear solid state NMR", defended on 1998 at the University of Le Mans (France). From 1999 to 2006, he was Associated Professor in the "Glasses and Ceramics Laboratory" of the University of Rennes. After his accreditation to supervise research devoted to "optical and structural properties of non-conventional glasses", he is Full Professor in charge of the passive optic group working on infrared optical fibers for sensors. He is also a solid-state NMR expert and is responsible for several international research programs. He is author and co-author of about 100 publications and more than 20 invited lectures.

Dr. V. Nazabal got her PhD degree in Solid State Chemistry from the University of Bordeaux (France) in 1999 after a master at Ecole Normale Superieure, at University of Paris VI. She joined the NIMS (Tsukuba, Japan) as post-doctoral fellowship in 2000. She belongs to the CNRS since 2001 and got accreditation in 2009. Her research activity is performed at the Glasses \& Ceramics team of the Chemical Sciences Institute at the University of Rennes (France) with more than 100 publications as author or co-author and several invited contributions in international conferences. She received in 2010 a bronze medal of CNRS. 


\section{Figure.captions}

Figure 1. $(\mathrm{A}): \mathrm{Pr}^{3+}$ : GaGeSbS near IR absorption cross section, calculated from the 1000 ppm doped glass spectrum. (B): mid-IR absorption cross-section and emission cross-section calculated using the reciprocity method

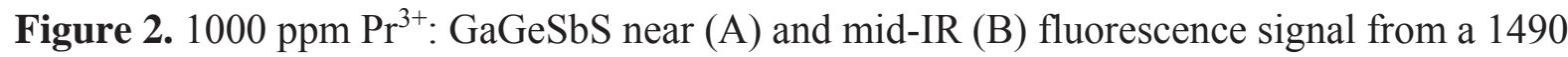
nm pumping. Inset: scheme of the major contributions.

Figure 3. mid-IR emission lines comparison: 1.49 and $2.0 \mu \mathrm{m}$ optical pumping (A); fiber and bulk materials (B).

Figure 4. raw mid-IR emission spectrum of a $500 \mathrm{ppm}$ doped $\mathrm{Pr}^{3+}: \mathrm{Ga}_{5} \mathrm{Ge}_{20} \mathrm{Sb}_{10} \mathrm{~S}_{65}$ fiber for several lengths. The $1490 \mathrm{~nm}$ pump power is of $800 \mathrm{~mW}$. The $1490 \mathrm{~nm}$ pump power is fixed at about $800 \mathrm{~mW}$.

Figure 5. $\mathrm{Pr}^{3+} \mathrm{GaGeSbS}$ bulk glasses experimental lifetimes versus the $\mathrm{Pr}^{3+}$ concentration, ranging from $500 \mathrm{ppm}$ to $3000 \mathrm{ppm}$ (pumping at $1650 \mathrm{~nm}$ ).

Figure 6. Glass tank containing chloroform with fiber mounted inside, side and top view.

Figure 7. Propagation of the light in a raw and a tapered fiber.

Figure 8. Experimental setup for detection of chloroform.

Figure 9. (A) Liquid chloroform infrared absorption spectra recorded by FTIR spectrophotometer (Red box: detected absorption band). (B) Pr: GaGeSbS mid-IR emission band and chloroform absorption at $4.1 \mu \mathrm{m}$.

Figure 10. FEWS experimentations results: 5000 ppm doped fiber (A) and 1000 ppm doped fiber (B). 
Fig.1
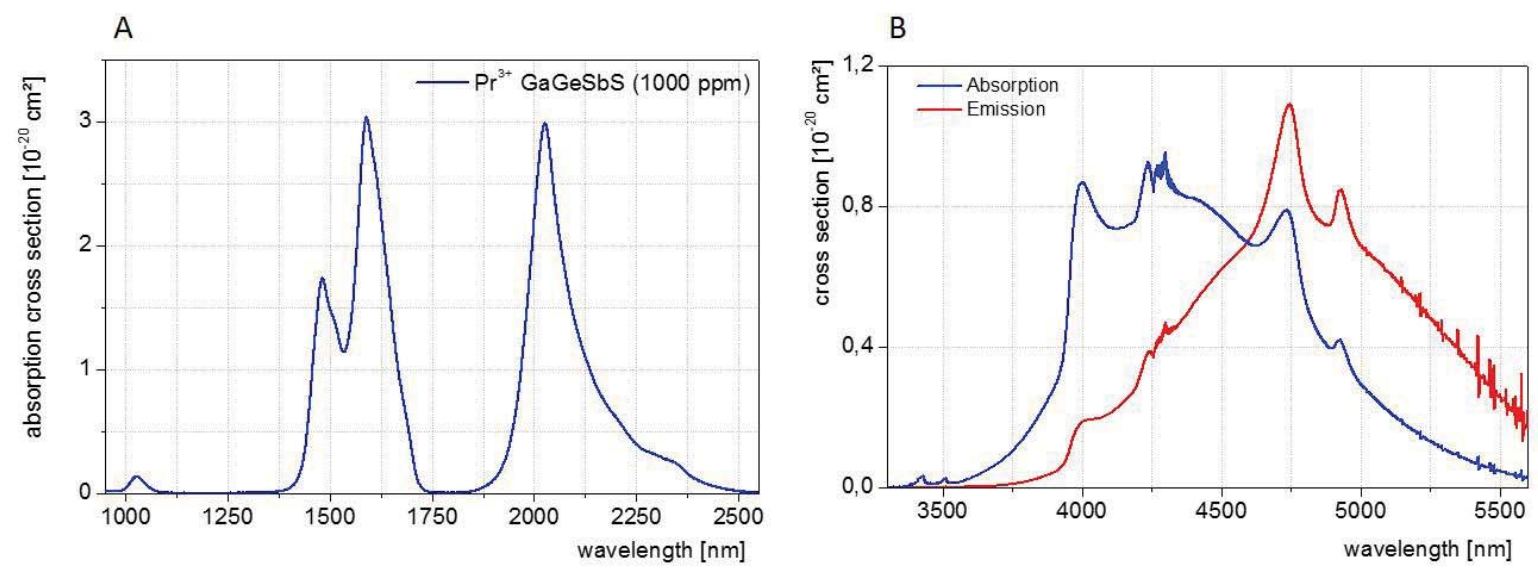

Fig.2

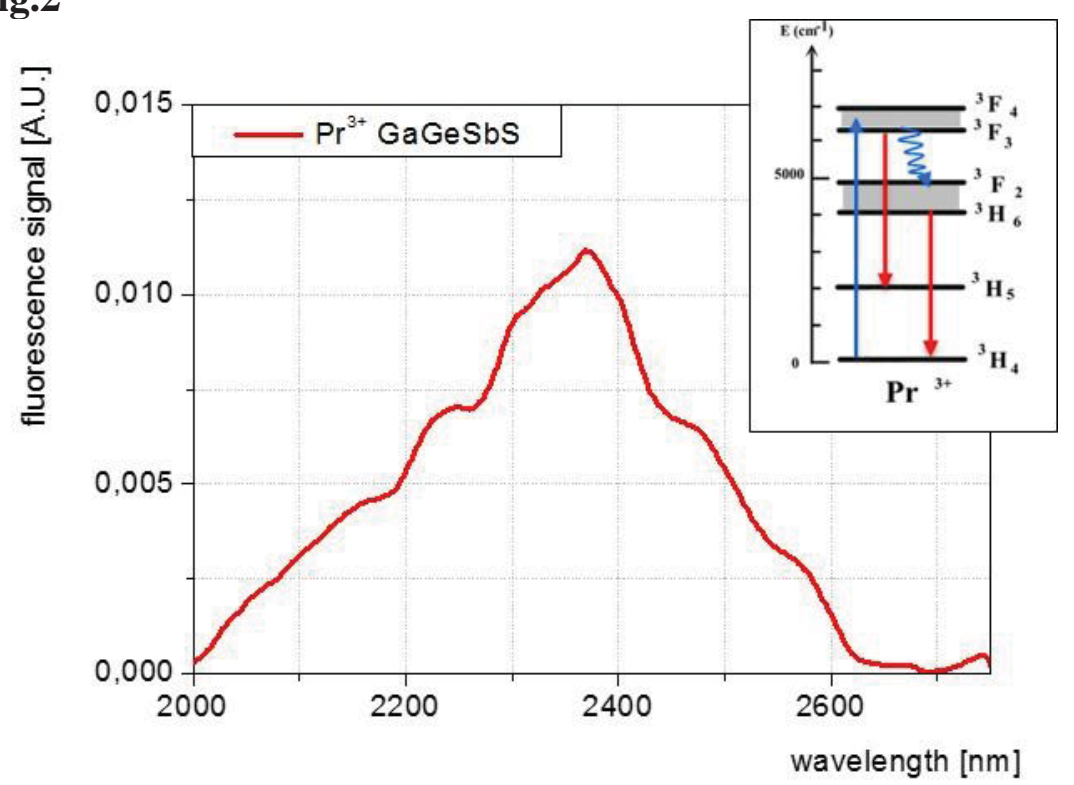


Fig.3
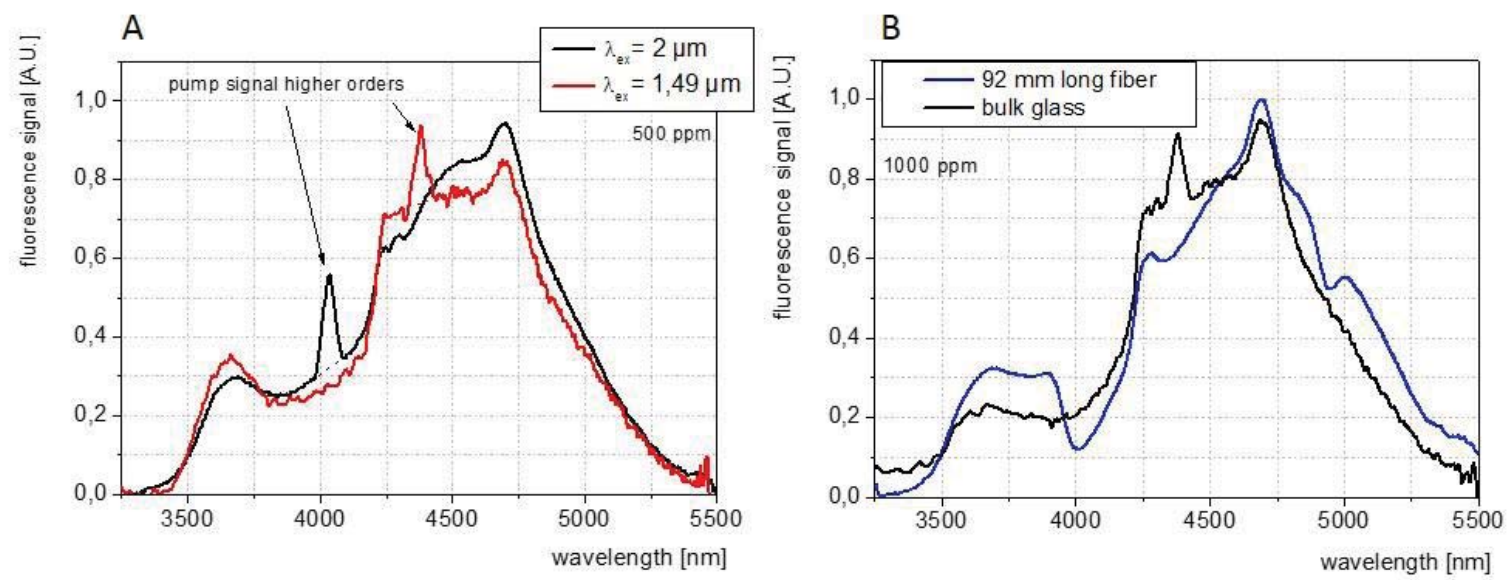

Fig.4

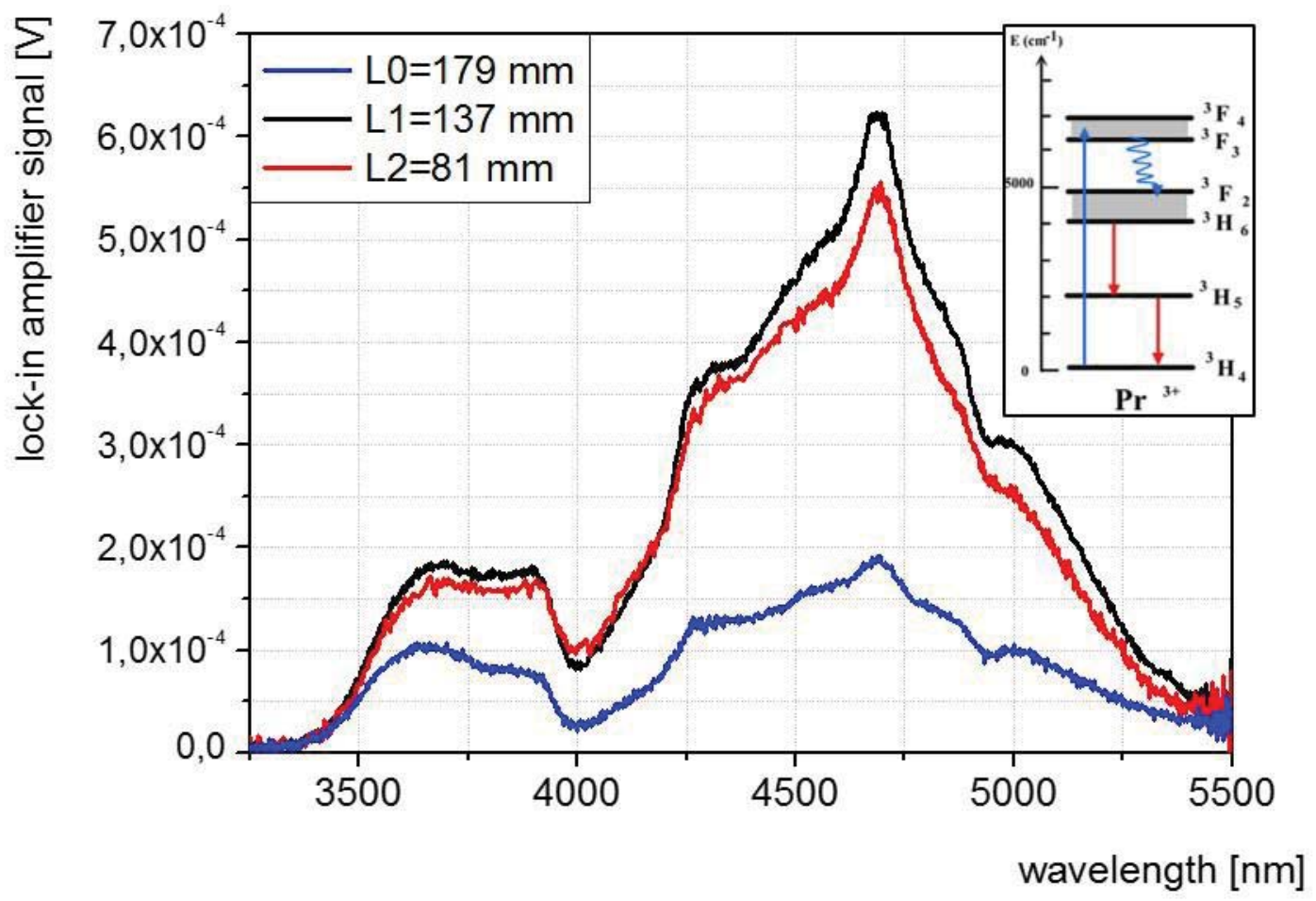


Fig.5

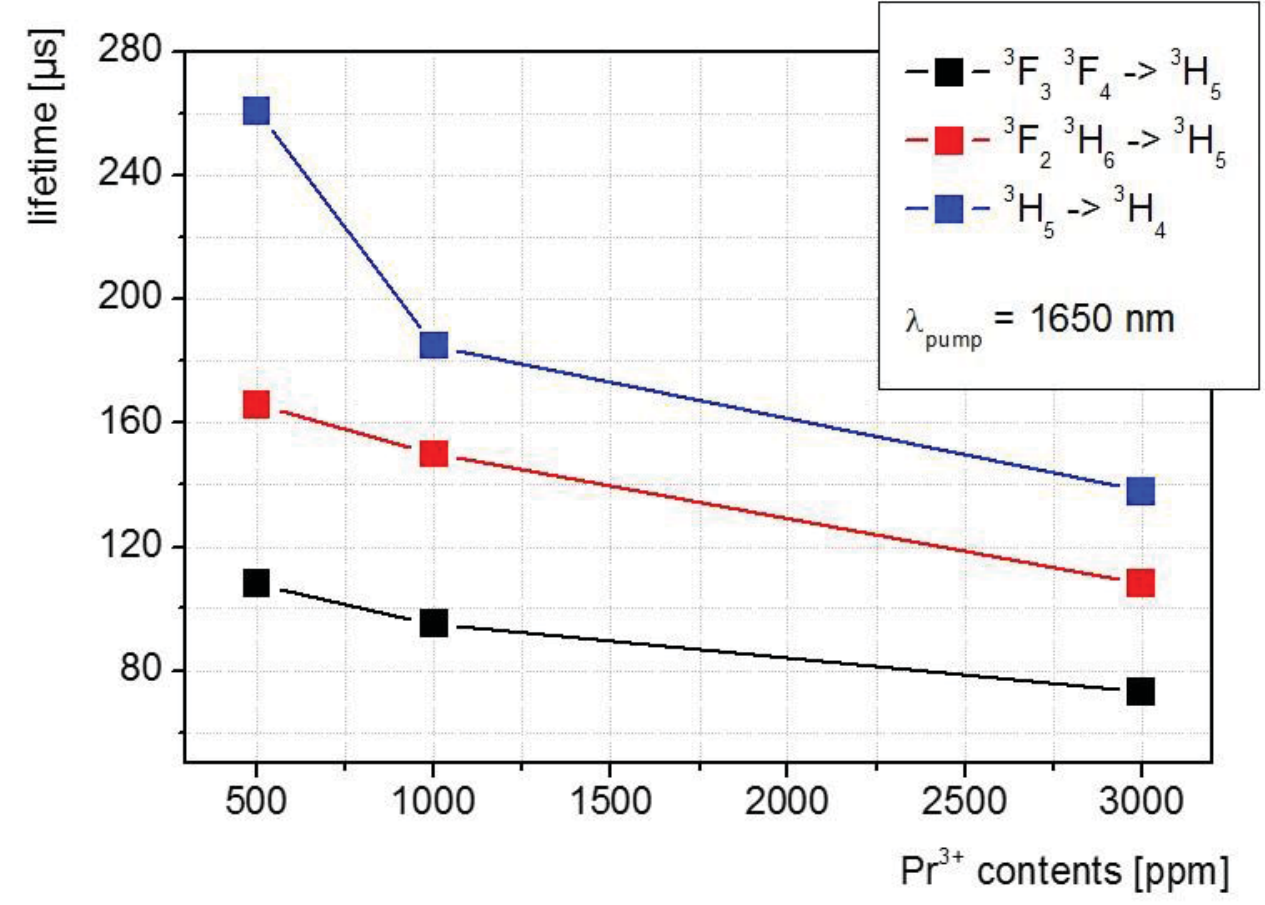

Fig.6

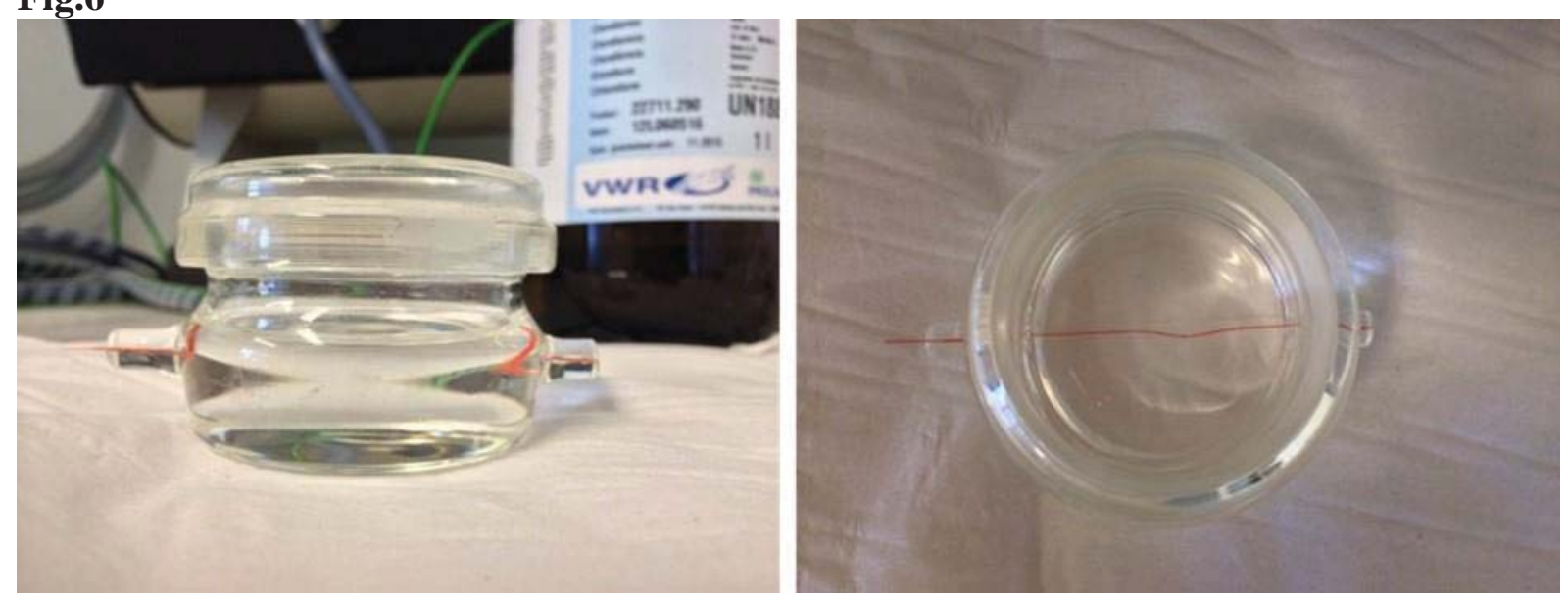


Fig.7

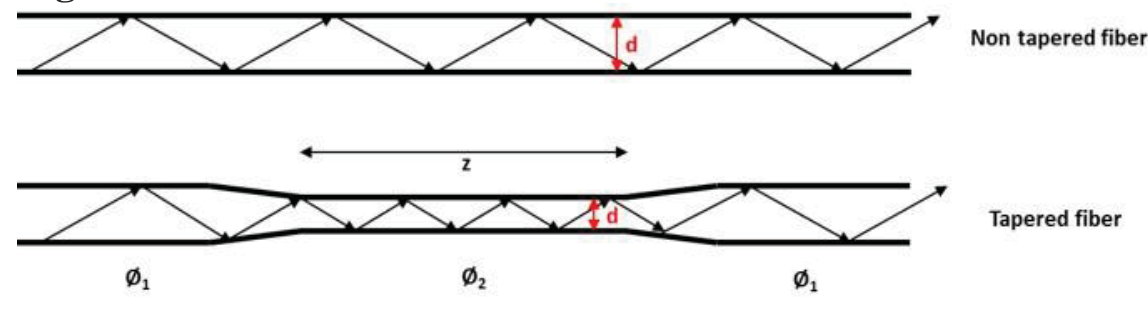

Fig.8

$2 \mu \mathrm{m} \mathrm{Tm}{ }^{3+}:$ YAG laser

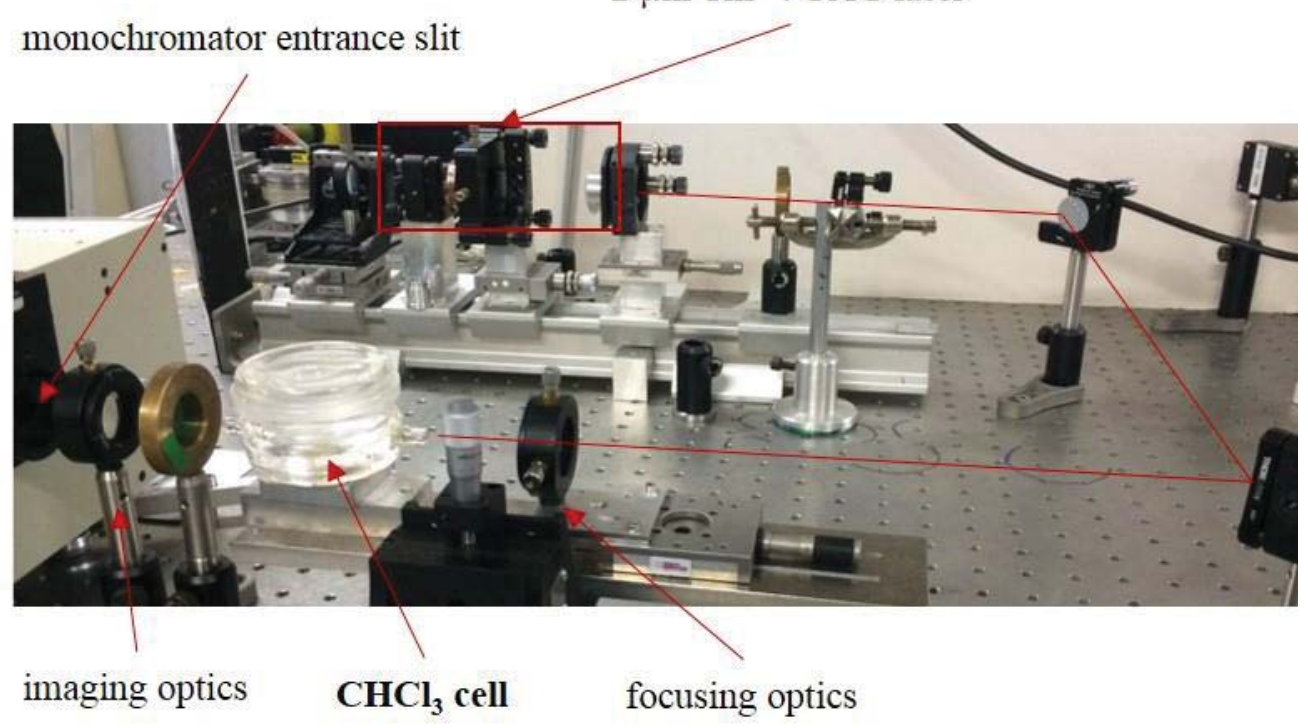


Fig.9
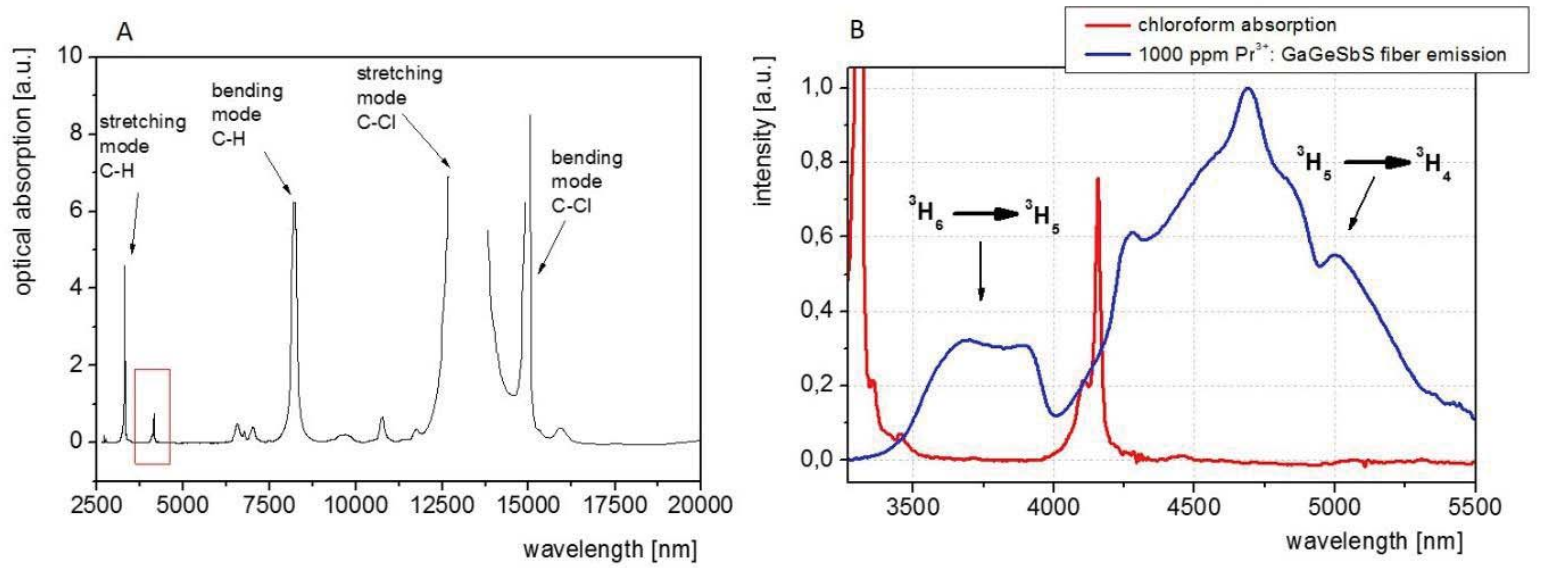

Fig.10
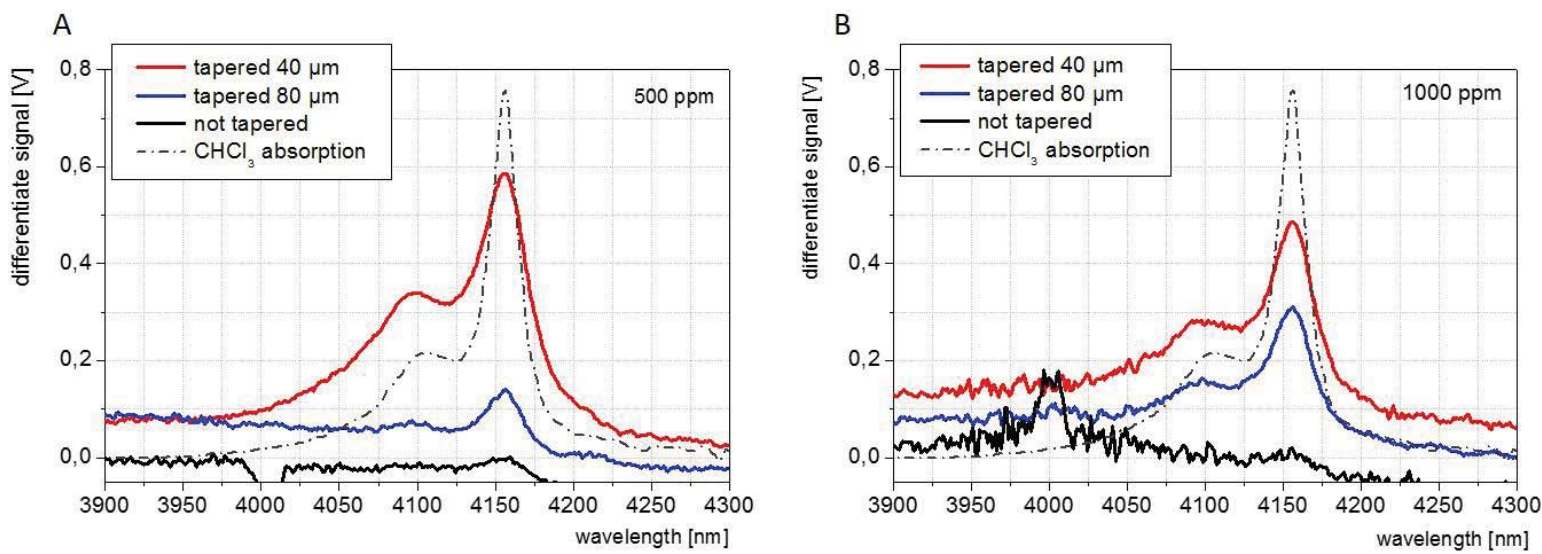
Table 1. $\mathrm{Pr}^{3+}$ : $\mathrm{Ga}_{5} \mathrm{Ge}_{20} \mathrm{Sb}_{10} \mathrm{~S}_{65}$ Judd-Ofelt analysis report for the near and mid-IR involved transitions. Transitions with a branching ratio less than $5 \%$ are not listed ( $\lambda_{\mathrm{em}}$ is the mean wavelength, $\tau_{\text {rad }}$ the radiative lifetime, and $\beta$ the branching ratio).

\begin{tabular}{|r|r|r|l|}
\hline Tra & $\lambda_{\mathrm{e}}$ & $\tau_{\mathrm{r}}$ & \\
\hline${ }^{3} \mathrm{H}_{5}$ & 4 & 1 & \\
\hline${ }^{3} \mathrm{H}_{6}$ & 4 & 8 & \\
\hline${ }^{3} \mathrm{H}_{6}$ & 2 & & \\
\hline${ }^{3} \mathrm{~F}_{2}$ & 3 & 0 & \\
\hline${ }^{3} \mathrm{~F}_{2}$ & 2 & & \\
\hline${ }^{3} \mathrm{~F}_{3}$ & 2 & 0 & \\
\hline
\end{tabular}

